\title{
Cultivar and Year-to-Year Variation of Phytosterol Content in Rye (Secale cereale L.)
}

\author{
Marianne Zangenberg, ${ }^{\dagger}$ Hanne Boskov Hansen $\stackrel{\ddagger}{\ddagger}, \S$ \\ JOHANNES R. JøRGENSEN," AND LARS I. HELLGREN*,† \\ Center for Advanced Food Science and Technical University of Denmark, Biocentrum-DTU, \\ Building 224, Søltofts Plads, Dk-2800 Kgs. Lyngby, Denmark, Center for Advanced Food Science and \\ Department of Dairy and Food Science, Royal Veterinary and Agricultural University, DK-1870 \\ Frederiksberg C, Denmark, and Department of Plant Biology, Research Centre Flakkebjerg, Danish \\ Institute of Agricultural Sciences, DK-4200 Slagelse, Denmark
}

\begin{abstract}
Intake of phytosterols (and -stanols) has been shown to decrease the level of low-density lipoprotein cholesterol and thus protect against development of cardiovascular diseases. Therefore, studies on the cultivar and year-to-year variation in phytosterol content in rye grains have been performed. The phytosterol content and composition of different rye cultivars, grown under identical conditions on the same field in three consecutive years, were analyzed. Both cultivar and year-to-year variation in sterol content were statistically significant $(p<0.0001)$. The total sterol content varied from $1007 \pm$ $21 \mathrm{mg} / \mathrm{kg}$ in the highest yielding cultivar, Tsulpan 3, to $761 \pm 10 \mathrm{mg} / \mathrm{kg}$ in the lowest yielding cultivar (Amando in the 1999 harvest). Because the meteorological conditions varied substantially between the different years, it was possible to deduce the impact of varying weather conditions on phytosterol content in the different cultivars. The studied cultivars had all the lowest phytosterol contents in the dry and warm harvest season of 1999. Although there were statistically significant cultivar and yearto-year variations in the sterol composition $(p<0.0001)$, these were only between 2 and $4 \%$ of the total sterol content.
\end{abstract}

KEYWORDS: Sitosterol; campesterol; sitostanol

\section{INTRODUCTION}

Phytosterols (in present paper, this term also includes their saturated forms, phytostanols, if not otherwise stated) are a group of cholesterol-like molecules that has gained considerable interest during the past decade. Phytosterols are characterized by the occurrence of a methyl or ethyl group in carbon 24 of the basic cholesterol molecule (see Figure 1).

The present interest in phytosterols is mainly due to the fact that dietary phytosterols inhibit cholesterol absorption, which leads to decreased plasma low-density lipoprotein (LDL) cholesterol levels and thereby a potentially decreased risk of developing cardiovascular diseases $(1,2)$. Furthermore, several studies report that phytosterols might protect against development of colon cancer, both in murine models and in human in vitro models (3). It has also been claimed that low doses $(60$ $\mathrm{mg} /$ day) of phytosterols have a positive impact on the human immune system (4), and in clinical trials, it has been shown

* To whom correspondence should be addressed. Tel: +4545252759 . Fax: +45 45886307. E-mail: lih@biocentrum.dtu.dk.

Center for Advanced Food Science and Technical University of Denmark.

$\doteqdot$ Royal Veterinary and Agricultural University.

$\S$ Present address: The Danish Veterinary and Food Administration, Mørkhøj Bygade 19, DK-2860 Søborg, Denmark.

" Danish Institute of Agricultural Sciences.

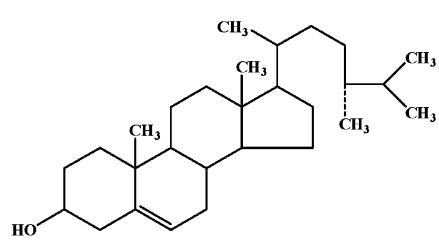

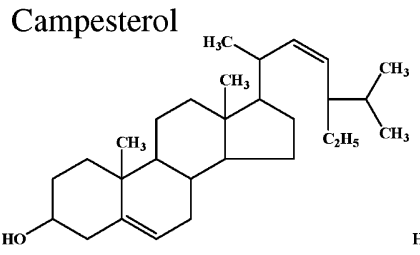

Sitosterol<smiles>CC(C)CCC(C)C1CCC2C3CC=C4C[C@@H](C)CC[C@]4(C)C3CC[C@]12C</smiles>

Stigmasterol

Cholesterol

Figure 1. Chemical structures of the phytosterols discussed in the present paper. The structure of cholesterol is also included for comparison. The phytostanols, campestanol and sitostanol, are the saturated forms of campesterol and stigmasterol or sitosterol, respectively.

that intake of phytosterols decreases the symptoms of benign prostata hyperplasi (5). Thus, intake of phytosterols has an array of potential health-promoting effects and several phytosterolenriched functional food products are commercially available in Europe and the U.S. today. It has been clearly shown that 


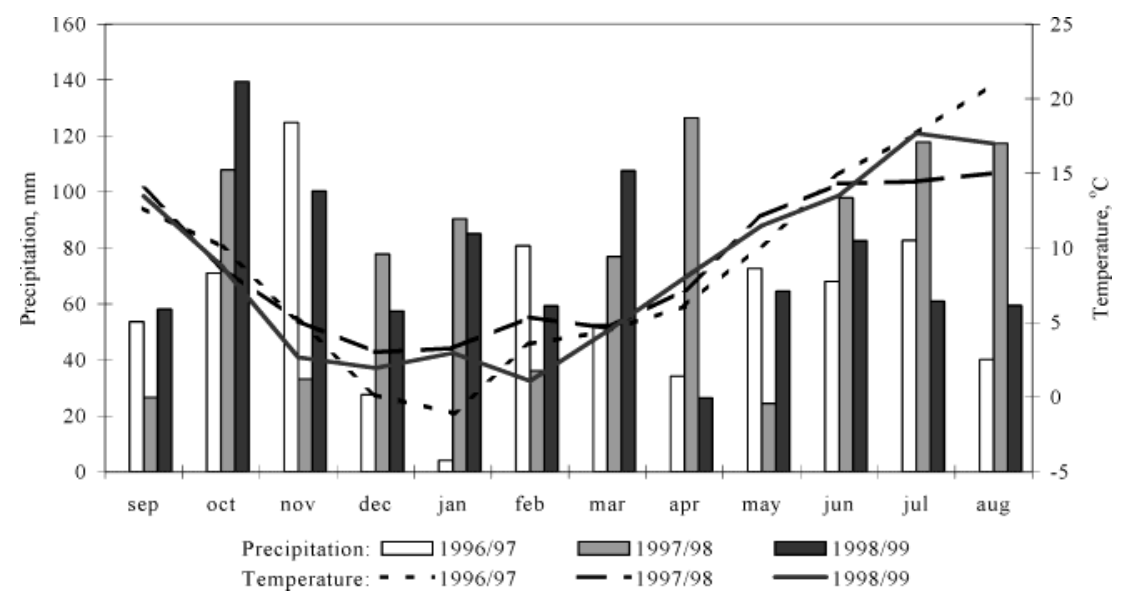

Figure 2. Mean precipitation $(\mathrm{mm})$ and mean temperature $\left({ }^{\circ} \mathrm{C}\right)$ of The Danish Agricultural Research Centre, Rønhave, in the $1996-1999$ growing seasons.

these products decrease the plasma LDL cholesterol level, when eaten on a daily basis $(6,7)$. The daily phytosterol intake from these products is typically around $2 \mathrm{~g}$, while the intake from natural sources normally is between 200 and $400 \mathrm{mg} /$ day (8).

It has been argued that intake of naturally occurring phytosterols is without interest on cholesterol absorption and blood lipid composition, since an intake of above $1 \mathrm{~g} /$ day is required to obtain the positive effects (9). However, this view has recently been challenged, since several published papers have shown that much lower concentrations of phytosterols have an effect, when administrated in a more suitable matrix $(10,11)$. In earlier studies, phytosterols were administrated in a triglyceride matrix, which also is the matrix in most commercial products. However, when the phytosterols were administrated as components of a phospholipid or diacylglycerol mixture, cholesterol absorption, serum cholesterol level, and development of atherosclerotic plaques decreased significantly, also at intakes corresponding to the natural consumption or just moderately increased (1013). Furthermore, it was recently shown that selectively removing the phytosterols from wheat germ, which was used as a component in a test meal (phytosterol content in the control diet with phytosterols was $330 \mathrm{mg}$ ), causes a $40 \%$ increase in cholesterol absorption (12). Thus, it is likely that the present natural intake of phytosterols alters cholesterol metabolism in a suitable direction in man and that relatively modest increases in this intake could improve public health.

The major sources of dietary phytosterols are vegetable oils and cereals (14). While the sterols are consumed in a triglyceride matrix in vegetable oils, the lipid fraction of cereals contains a larger portion of membrane forming lipids (phospholipids and glycolipids), which potentially could make the phytosterol intake from cereals more efficient in lowering plasma LDL cholesterol. Among the cereals, rye has been reported to be the best source of phytosterols (15). Thus, rye is probably an important source of plant sterols in food cultures where rye bread is a staple food, and increasing the concentration in bread rye would be advantageous.

Although some studies on the phytosterol content in cereals and cereal products have been published recently $(15-17)$ and Piironen et al. have published data on the phytosterol content in 11 different rye cultivars, which were grown in the same area of Finland (15), we still lack information on cultivar and year-to-year variation in rye grown in the same field. Therefore, we have analyzed the sterol content in rye grain from six different cultivars, grown under identical conditions in one year and from three different cultivars grown in the same field for three consecutive years. Because the weather conditions varied substantially during the studied years, the results also indicate how climatic factors affect the content of phytosterols in cereals.

\section{MATERIAL AND METHODS}

Materials. $\mathrm{CHCl}_{3}$ and methanol were from J. T. Baker (Deventer, NL). Ethyl acetate, 2-propanol, and heptane were of high-performance liquid chromatography (HPLC) grade and from Rathburn (Walkerburn, U.K.). Ethanol, phosphoric acid, and all authentic sterol standards except campesterol, sitostanol, and stigmasterol were purchased from Sigma (St. Louis, MO). Campesterol, sitostanol, and stigmasterol were from Matreya, Inc. (Pleasant Gap, PA). All other chemicals as well as thinlayer chromatography (TLC) plates (Silica Gel 60) were from Merck (Darmstadt, Germany). The purities for the standards were [as determined by gas chromatography-flame ionization detection (GCFID) (results not shown)] as follows: cholesterol $>99 \%$; cholestanol, 97\% (impurities were cholesterol); campesterol, $97 \%$; $\beta$-sitosterol, $98 \%$; sitostanol, 98\%; and stigmasterol, $98 \%$.

Rye Samples. The cultivars were grown at Ronhave Experimental Station (Danish Institute of Agricultural Science); the growing site, culture conditions, experimental design, and sampling have been described (18). The samples were sown in the end of September 1996, 1997, and 1998 and were harvested in the middle of August 1997, 1998, and 1999, respectively. The falling number of the rye cultivars was on average for the three harvest years as follows: 1997, $242 \pm 49$ s; $1998,129 \pm 44 \mathrm{~s} ; 1999,287 \pm 29$ s. The climate of three years represented conditions contrasting each other (Figure 2). The summer of 1997 and the harvest period in August were relatively warm and dry. The summer and the harvest time in 1998, however, were rainy, and the summer of 1999 was very warm. The degree of lodging was high in 1997 field plots, which was the reason for lowering the nitrogen supply from $150 \mathrm{~kg} / \mathrm{ha}$ in 1996/1997 to $130 \mathrm{~kg} / \mathrm{ha}$ in the two following years. In 1998, the degree of lodging was also high, but this was explained by the wet climate of this year. In 1999, practically no lodging occurred except for the cultivar Tsulpan3.

Sample Preparation. Grain samples were milled on a hammer type cyclone mill (Laboratory mill 120, Perten Instruments, Huddinge, Sweden) with a $0.5 \mathrm{~mm}$ sieve before analysis. The flour was immediately frozen at $-20{ }^{\circ} \mathrm{C}$ and stored at $-20{ }^{\circ} \mathrm{C}$ until analyzed.

Sterol Extraction. A $150-200 \mathrm{mg}$ amount of flour was weighed into Teflon-lined screw-capped glass tubes, $3 \mathrm{~mL}$ of $2.0 \mathrm{M} \mathrm{HCl}$ in ethanol and $55 \mu \mathrm{g}$ of cholestanol in ethyl acetate (internal standard) were added, and the sample was mixed and incubated in a water bath at $80{ }^{\circ} \mathrm{C}$ for $60 \mathrm{~min}$. This treatment hydrolyzed the glycosidic bonds between sterol and glucose in the sterol-glycosides (19). The samples were cooled, and $1.00 \mathrm{~mL}$ of $33 \% \mathrm{KOH}$ was directly added, followed by $60 \mathrm{~min}$ of incubation on a water bath at $80^{\circ} \mathrm{C}$. The alkaline hydrolysis hydrolyzes the ester bond between the fatty acids and the hydroxyl group of the sterol in sterolesters. Total hydrolysis of 
sterolesters was verified using HPTLC analysis. Following the alkaline hydrolysis, the samples were cooled; $3.0 \mathrm{~mL}$ of double-distilled $\mathrm{H}_{2} \mathrm{O}$ and $3.0 \mathrm{~mL}$ of $\mathrm{CHCl}_{3}$ were added. The tubes were mixed and centrifuged for $5 \mathrm{~min}$ at $4000 g_{\max }$ to ensure phase separation. The organic phase was transferred to a new glass, and the aqueous phase was re-extracted twice with $3.0 \mathrm{~mL}$ of $\mathrm{CHCl}_{3}$. The extract was dried down under $\mathrm{N}_{2}$ and dissolved in $500 \mu \mathrm{L}$ of $\mathrm{CHCl}_{3}: \mathrm{MeOH}$ [2:1 (v:v)].

Sterol Purification. The extract was applied on a TLC plate, and the plate was developed in a filter paper-lined TLC chamber using heptane:2-propanol: $\mathrm{NH}_{4} \mathrm{OH}(90: 12: 0.5)$ as eluent. The dry plate was sprayed with water until soaked, the band corresponding to the cholesterol standard was scraped into a screw-capped tube, and 2.35 $\mathrm{mL}$ of $\mathrm{MeOH}$ and $150 \mu \mathrm{L}$ of $33 \% \mathrm{KOH}$ were added. The tube was incubated for $10 \mathrm{~min}$ at $60^{\circ} \mathrm{C}$. This alkaline treatment partly dissolves the silica gel, which substantially increases the extraction efficiency of sterols from the TLC plate. The tubes were cooled, and the sterols were extracted by the addition of $4.7 \mathrm{~mL}$ of $\mathrm{CHCl}_{3}$ and $1.25 \mathrm{~mL}$ of $\mathrm{ddH}_{2} \mathrm{O}$. The lower phase was collected, and the upper phase was reextracted once with $2.0 \mathrm{~mL}$ of $\mathrm{CHCl}_{3}: \mathrm{MeOH}$ [85:15 (v:v)]. The solvents were evaporated, and the sample was dissolved in $200 \mu \mathrm{L}$ of ethyl acetate.

Gas-Liquid Chromatography and Identification of Sterols. The nonderivatized sterols were analyzed using GLC-FID on a HewlettPackard 5890 Series 2, controlled by the HP ChemStation (Rev A.03.06[509]) software package. When internal standard was used and raw data were corrected for the differing response factors for the different sterols, this method gave identical results as analyzing the TMSethersterol derivate (unpublished results). The sterols were separated on a $30 \mathrm{~m}$ Phenomex Zebron Zb-5 (Ca, U.S.A.) (i.d. $0.25 \mathrm{~mm}$ and film thickness $0.25 \mu \mathrm{m}$ ) column, using a temperature program from 280 to $310^{\circ} \mathrm{C}$, with an increase of $5{ }^{\circ} \mathrm{C} / \mathrm{min}$. The initial temperature was held constant for $3 \mathrm{~min}$, and the final temperature was held constant for $10 \mathrm{~min}$. The GC settings were as follows: split injection (split ratio $1: 21$ ), the injector temperature was $280^{\circ} \mathrm{C}$, and helium was used as the carrier gas with a flow of $1.25 \mathrm{~mL} / \mathrm{min}$. The FID was operated at $310{ }^{\circ} \mathrm{C}$ with a hydrogen flow at $27 \mathrm{~mL} / \mathrm{min}$ and air flow at $315 \mathrm{~mL} /$ min. Sterols were identified based on retention time, using authentic standards [standards for cholesterol, cholestanol, campesterol, campestanol, stigmasterol, sitosterol, and sitostanol were available (see above)]. Because there is no commercial source of campestanol, it was produced from campesterol through chemical hydrogenation (20).

Quantification of Sterols. Sterols were identified using the retention times for the standard mixture described above. Quantification was based on peak areas for the different phytosterols as compared with the peak area of the internal standard. In each sample sequence analyzed, a quantitative standard containing cholesterol, cholestanol, campesterol, stigmasterol, sitosterol, and sitostanol was analyzed three times. Setting the peak area of cholestanol to 1, response factors for the other sterols were calculated. Calculated masses from the samples were corrected for the response factor. Because no quantitative standard was available for campestanol, a response factor was calculated based on the response factor for campesterol, adjusted using a factor obtained by dividing the response factors for cholesterol and cholestanol. The rationale behind this approach is that the structural differences between campesterol and campestanol are identical to the difference between cholesterol and cholestanol. Unidentified peaks occurring in the sterol part of the chromatogram are reported as "unidentified sterols", and because all of these occurred directly after sitostanol, they have been quantified using the response factor for sitostanol.

Validation of the Analytical Methods. The suitability of using cholestanol as internal standard was controlled by performing the extraction and purification steps described above on standard mixtures containing cholesterol, cholestanol, campesterol, campestanol, stigmasterol, sitosterol, and sitostanol at three different concentrations and in four replicates. After GC analysis of the mixture before and after extraction and purification, the percental distribution of the peak areas for the different sterols was compared. Because the peak area distribution between the sterols was identical before and after processing, basing the quantification on cholestanol area will compensate for any losses that occur during the extraction and purification process. However, the yield of the extraction and purification was also controlled

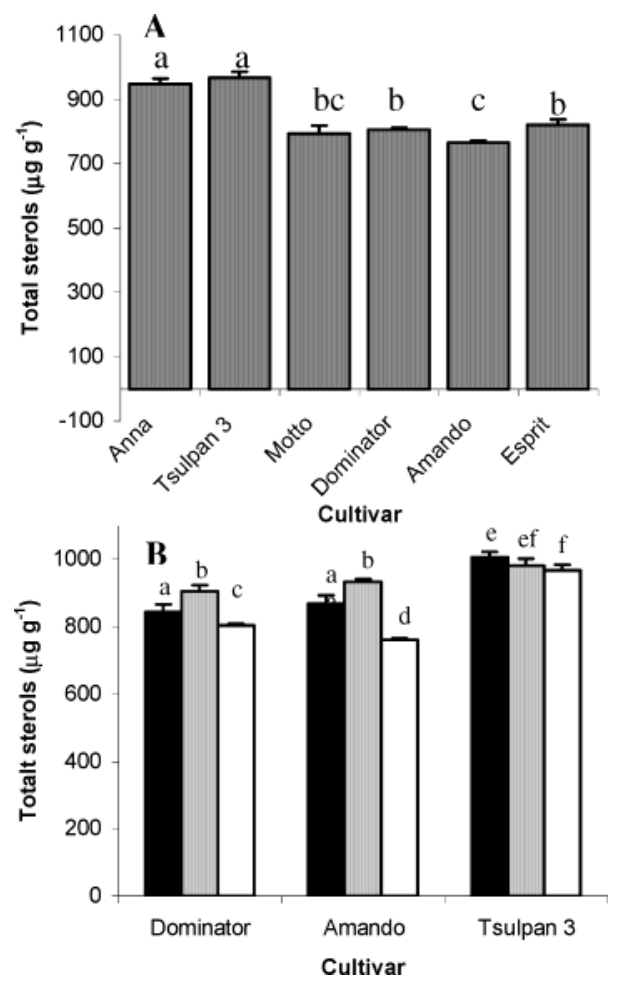

Figure 3. Total sterol content (includes campesterol, campestanol, stigmasterol, sitosterol, and sitostanol) in (A) kernels from six rye cultivars in harvest year 1999 and (B) three cultivars in harvest years 1997 (black), 1998 (gray), and 1999 (white). Error bars shows standard deviation. Columns with different letters above are statistically significant $(P<0.01)$, $n=4$.

by performing the extraction and purification on a sample spiked with ${ }^{3} \mathrm{H}$ cholesterol in four replicates. The yield of the process was $74 \pm$ $7 \%$. Intra- and interassay variability were determined by analyzing the same sample three times in five replicates in 1 day and analyzing the same sample in duplicate on five different occasions during a two month period. Intraassay variability never exceeded $2 \%$, and interassay variability did not exceed $6 \%$. In the presented results, analysis of replicates was always performed in different days; thus, standard deviations of the results contain interassay variability.

Statistical Treatment. Results are given as average \pm standard deviation $(n=4)$. The null hypothesis that there was no difference between the cultivars in the 1999 harvest was tested using one-way analysis of variance (ANOVA) followed by Tukey-Kramers post-hoc test. The null hypotheses that there was no interaction between cultivar and year, no difference between the cultivar or between the years, were tested using a model I two way ANOVA. When $p<0.01$, the difference was considered statistically significant. Year and variety were considered as fixed variables. All statistical analyses were performed using the software package GraphPad Prism (ver. 3.03) (GraphPad Software Inc., CA).

\section{RESULTS AND DISCUSSION}

Sterol Content. There was a statistical significant difference in sterol content, both between varieties in the 1999 harvest ( $p$ $<0.0001$; Figure 3A) and between the harvest years for the three cultivars, which were analyzed in three consecutive years ( $p<0.0001$ for Amando and Dominator and 0.01 for Tsulpan; Figure 3B). The highest phytosterol content in the harvest year 1999 occurred in the Russian population cultivar Tsulpan 3, which contained $967 \pm 15 \mathrm{mg} / \mathrm{kg}$, and in the Finnish population cultivar Anna, which contained $946 \pm 18 \mathrm{mg} / \mathrm{kg}$ (Figure 3A.). The German hybrid cultivar Amando contained the lowest amount, $761 \pm 5 \mathrm{mg} / \mathrm{kg}$, while intermediate amounts of plant sterols were found in the hybrid cultivar Esprit and the 

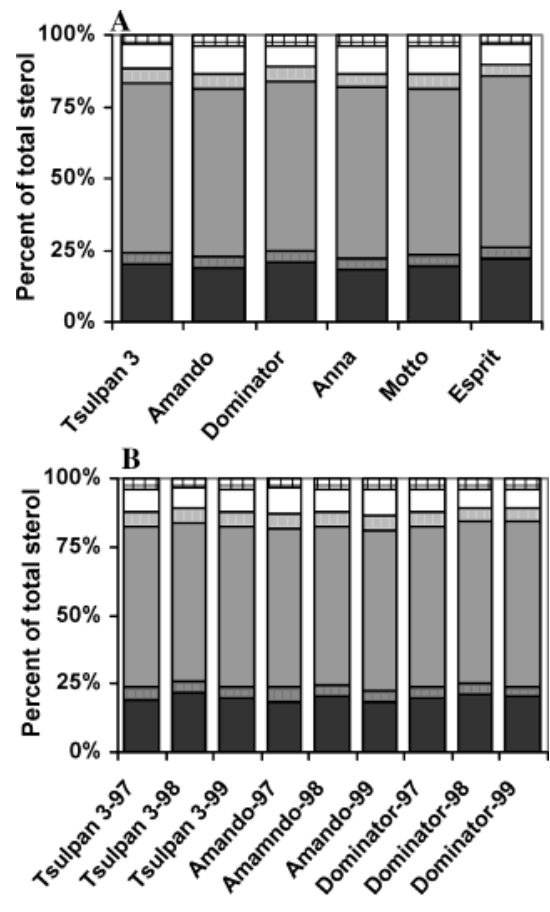

Cultivar

Figure 4. Sterol composition in (A) seven different rye cultivars in harvest year 1999 and (B) three different cultivars in harvest years 1997, 1998, and 1999. The distribution is given as percent of total sterols for (from the bottom) campesterol (black); stigmasterol (dark gray); sitosterol (intermediate gray); campestanol (light gray); sitostanol (white); and nonidentified sterols (hatched). Presented data are mean values from four independent analysis. The relative standard error of the mean never exceeded $3 \%$.

population cultivars Dominator and Motto (Figure 3A). The highest amount found in the entire study occurred in Tsulpan 3 in $1997(1007 \pm 14 \mathrm{mg} / \mathrm{kg})$, while the concentration found for Amando in 1999 was the lowest. Thus, there was about $25 \%$ difference in phytosterol content between highest and lowest content in the present study.

As has been discussed elsewhere, earlier studies on phytosterols in cereals have underestimated the content between 20 and $35 \%$, since the extraction methods used did not extract the sterol glycosides (19). To our knowledge, only two modern studies on the total phytosterol content in rye have been published so far: the study of Dutta and Appelqvist (1996), which contains data from mixed rye samples from Finland (17), and the study by Piironen et al., which have compared the phytosterol content of 11 different cultivars, grown at different sites in the same area in Finland (15). Because Dutta and Appelqvist only report sterol content as mg per g lipid, comparison with their study is not possible. However, Piironen et al. (2002) report the rye kernel phytosterol content to be between 707 and $989 \mathrm{mg} / \mathrm{kg}$ (15), with the highest concentration found in Anna (their study did not include Tsulpan 3). Because our result lies within the same range, although it includes partly different cultivars and the plants have been grown under different conditions, it may be concluded that the normal range of phytosterols in rye kernels is $700-1000 \mathrm{mg} / \mathrm{kg}$. Furthermore, it is evident that Anna is a cultivar with high phytosterol content, also under differing growth conditions.

Considering the year-to-year variation (Figure 3B), the results from model I two way ANOVA with cultivar and year as the factors, showed that there were interactions between cultivar and year $(P<0.001)$. The sterol concentration was consistently highest in Tsulpan 3, and there were only minor variations between the years in this cultivar, while the year-to-year variation was substantially higher in Dominator and Amando. These cultivars contained similar amounts in 1997 and 1998, while the sterol content in Amando was significantly $(p<0.01)$ lower in 1999. In all three cultivars, the phytosterol concentration was lowest in 1999 (however, the difference between 1998 and 1999 was not statistically significant in Tsulpan 3). In Amando and Dominator, the sterol content varied in the same way over the three years; it was highest in 1998, lowest in 1999, and intermediate in 1997. As earlier mentioned, the climate differed between the years; 1997 and 1999 were warm and dry, while 1998 was cool and wet (Figure 2). Thus, our results indicate that the extent of phytosterol deposition in the rye kernels is responsive to the climate and that the high temperature and low rainfall during the month up to harvest, which signified 1997 and 1999, caused a decrease in the total phytosterol concentration in the kernels, as compared with a situation of high precipitation and cool weather that occurred in 1998. To our knowledge, the impact of climatic factors on phytosterol concentration in cereal kernels has not been studied. However, growth location has a significant impact on phytosterol content in oat cultivars grown at three different locations in mid-Sweden (16), which shows that environmental factors affect phytosterol concentration in cereals. It has also been shown that the phytosterol content in greenhouse grown soybean seed increases with increasing temperature (21), while decreased growth medium water potential caused a decreased content of sterols in wheat leaves (22). Although the latter study is concerned with vegetative tissue, it suggests that decreased soil water potential also could explain the lower sterol content in the rye kernels in the dry years of 1997 and 1999, as compared with 1998.

Sterol Composition. The sterol composition was similar both between the different cultivars and between the years in the same cultivar (Figure 4). It was dominated by sitosterol and campesterol, while stigmasterol, campestanol, and sitostanol constituted minor fractions. On average in the entire study, sitosterol and campesterol constituted $59.0 \pm 0.8$ and $19.5 \pm$ $1.0 \%$ of the total sterol content, respectively; sitostanol constituted $8.4 \pm 1.0 \%$, and campestanol and stigmasterol consituted $5.1 \pm 0.5$ and $4.2 \pm 0.6 \%$, respectively (not shown). This is similar to the composition of rye sterols published by Piironen and colleagues, although they report slightly less sitosterol and more sitostanol and campestanol (15). There were statistical significant differences in distribution of the sterol species between the different cultivars, but for the campesterol, sitosterol, and stigmasterol, the differences were below $2 \%$ of the total sterols, which is considered to be without any biological significance. The highest variation was found in the total stanols; in Esprit, stanols contributed $11.0 \%$ of the total sterols, while they contributed 14.5-14.8\% in Amando, Anna, and Motto (Figure 3). Furthermore, when the sterol fractions from three consecutive harvest years were analyzed for Amando, Dominator, and Tsulpan 3, Amando contained the highest total stanols percentage in all three years (Figure 3B). Interestingly, when Piironen et al. studied the phytosterol composition of 11 different rye cultivars grown in Finland, Amando had the highest percentage of stanols also among these. Although the differences are small, it indicates that there are genetic differences between Amando and the other cultivars that could be exploited in producing cultivars with increased stanol content. This could be of interest, since the efficiency in reducing plasma cholesterol 
is similar for phytostanols and phytosterols (23), while the intestinal absorption of phytostanols is much lower (24), and it recently has been shown that increased plasma concentrations of sitosterol and campesterol could be a risk factor for development of cardiovascular diseases (25). All three analyzed cultivars showed the same pattern of year-to-year variation in stanols vs sterol content. The lowest stanol content was found in the year with lowest average temperature and highest rainfall (1998) (Figures 2 and 3B), indicating that also climatic factors do affect the distribution between sterols and stanols in the rye kernel.

In conclusion, the phytosterol content in rye varies between different cultivars and between growing seasons. Tsulpan 3 contained the highest sterol concentration in all three years studied, and Tsulpan 3 was also the cultivar with the lowest year-to-year variation in sterol content. Thus, Tsulpan 3 would be a suitable cultivar to focus on in a breeding program aiming at increasing the phytosterol concentration in rye.

\section{LITERATURE CITED}

(1) Gylling, H.; Siimes, M. A.; Miettinen, T. A. Sitostanol ester margarine in dietary treament of children with familial hypercholesterolemia. J. Lipid Res. 1995, 36, 1807-1812.

(2) Ntanios, F. Y.; van de Kooij, A. J.; de Deckere, E. A. M.; Duchateau, G. S. M. J. E.; Trautwein, E. A. Effects of various amounts of dietary plant sterol esters on plasma and hepatic sterol concentration and aortic foam cell formation of cholesterol-fed hamsters. Atherosclerosis 2003, 169, 41-50.

(3) Awad, A. B.; Fink, C. S. Phytosterols as anticancer dietary components: Evidence and mechanism of action. J. Nutr. 2000, 130, 2127-2130.

(4) Bouic, P. J. D.; Clark, A.; Lamprecht, J.; Freestone, M.; Pool, E. J.; Liebenberg, R. W.; Kotze, D.; van Jaarsveld, P. P. The effects of B-sitosterol (BSS) and B-sitosterol glucoside (BSSG) mixture on selected immune parameters of marathon runners: Inhibition of post marathon immune suppression and inflammation. Int. J. Sports Med. 1999, 20, 258-262.

(5) Berges, R. R.; Windeler, J.; Trampisch, H. J.; Senge, T. Randomised, placebo-controlled, double -blind clinical trial of $\beta$-sitosterol in patients with benign prostatic hyperplasia. Lancet 1995, 345, 1529-1532.

(6) Weststrate, J. A.; Meijer, G. W. Plant sterol-enriched margarines and reduction of plasma total and LDL-cholesterol concentrations in normochoelsterolaemic and mildly hypercholesterolaemic subject. Eur. J. Clin. Nutr. 1998, 52, 334-343.

(7) Gylling, H.; Puska, P.; Vartiainen, E.; Miettinen, T. A. Serum sterols during stanol ester feeding in a mildly hypercholesterolemic population. J. Lipid Res. 1999, 40, 593-600.

(8) de Vries, J. H. M.; Jansen, A.; Kromhout, D.; van de Bovenkamp, P.; van Staveren, W. A.; Mensink, R. P.; Katan, M. B. The fatty acid and sterol content of food composites of middle aged men in seven countries. J. Food Compos. Anal. 1997, 10, 115-141.

(9) Hallikainen, M. A.; Sarkkinen, E. S.; Uusitupa, M. I. Plant stanol esters affect serum cholesterol concentrations of hypercholesterolemic men and women in a dose-dependent manner. $J$ Nutr. 2000, 130, 767-776.
(10) Meguro, S.; Higashi, K.; Hase, T.; Honda, Y.; Otsuka, A.; Tokimitsu, I.; Itakura, H. Solubilization of phytosterols in diacylglycerol versus triacylglycerol improves the serum cholesterol-lowering effect. Eur. J. Clin. Nutr. 2001, 55, 513-517.

(11) Ostlund, R. E., Jr.; Spilburg, C. A.; Stenson, W. F. Sitostanol administrated in lecithin micelles potently reduces cholesterol absorption in humans. Am. J. Clin. Nutr. 1999, 70, 826831.

(12) Ostlund, R. E., Jr.; Racette, S. B.; Stenson, W. F. Inhibition of cholesterol absorption by phytosterol-replete wheat germ compared with phytosterol-depleted wheat germ. Am. J. Clin. Nutr. 2003, 77, 1385-1389.

(13) Meguro, S.; Hase, T.; Otsuka, A.; Tokimitsu, I.; Itakura, H. Effect of phytosterols in dietary diacylglycerol on atherosclerosis in cholesterol-fed rabbits. Nutrition 2003, 19, 670-675.

(14) Piironen, V.; Toivo, J.; Lampi, A.-M. Natural sources of plant sterols. J. Food Compos. Anal. 2000, 13, 619-624.

(15) Piironen, V.; Toivo, J.; Lampi, A. M. Plant sterols in cereals and cereal products. Cereal Chem. 2002, 79, 148-154.

(16) Määttä, K.; Lampi, A.-M.; Petterson, J.; Fogelfors, B. M.; Piironen, V.; Kamal-Eldin, A. Phytosterol contents in seven oat cultivars grown at three locations in Sweden. J. Sci. Food Agric. 1999, 79, 1021-1027.

(17) Dutta, P.; Appelqvist, L.-Å. Saturated sterols (stanols) in unhydrogenated and hydrogenated edible vegetable oils and in cereal lipids. J. Sci. Food Agric. 1996, 71, 383-391.

(18) Boskov Hansen, H.; Rasmussen, C. V.; Bach Knudsen, K. E.; Hansen, A. Effects of genotype and harvest year on content and composition of dietary fibre in rye (Secale cereale L) grain. $J$. Sci. Food Agric. 2002, 83, 76-85.

(19) Jonker, D.; Hoek, G. D. v. d.; Glatz, J. F. C.; Homan, C.; Posthumus, M. A.; Katan, M. B. Combined determination of free,esterified and glycosilated plant sterols in food. Nutr. Rep. Int. 1985, 32, 943-951.

(20) Nace, H. An improved hydrogenation of cholesterol to cholestanol. J. Am. Chem. Soc. 1951, 73, 2379-2379.

(21) Vlahakis, C.; Hazebroek, J. Phytosterol accumulation in canola, sunflower, and soybean oils: Effects of genetics, planting location, and temperature. J. Am. Oil Chem. Soc. 2000, 77, 4953.

(22) Navar-Izzo, F.; Milone, M. T.; Quartacci, M. F.; Pinzino, C. Metabolic changes in wheat plants subjected to a water - deficit stress program. Plant Sci. 1993, 92, 151-157.

(23) Hallikainen, M. A.; Sarkkinen, E. S.; Gylling, H.; Erkkila, A. T.; Uusitupa, M. I. Comparison of the effects of plant sterol ester and plant stanol ester- enriched margarines in lowering serum cholesterol concentrations in hypercholesterolaemic subjects on a low-fat diet. Eur. J. Clin. Nutr. 2000, 54, 715-725.

(24) Heinemann, T.; Axtmann, G.; Bergmann, K. v. Comparison of intestinal absorption of cholesterol with different plant sterols in man. Eur. J. Clin. Invest. 1993, 23, 827-831.

(25) Sudhop, T.; Gottwald, B. M.; von Bergmann, K. Serum plant sterols as a potential risk factor for coronary heart disease. Metabolism 2002, 51, 1519-1521.

Received for review October 14, 2003. Revised manuscript received February 27, 2004. Accepted March 1, 2004.

JF0351873 